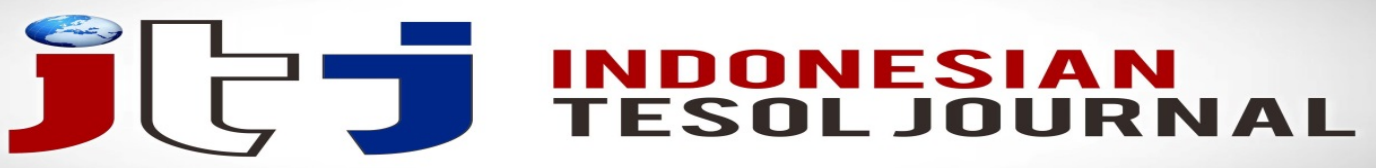

e-ISSN: 2622-5441(Online) Journal homepage: https://ejournal.iainpalopo.ac.id/index.php/ITJ/index

\title{
Spoken Error Correction Practices and Beliefs of EFL University Teachers in Saudi Arabia
}

\author{
Hira Hanif \\ Princess Nourah Bint Abdul Rahman University, Saudi Arabia
}

Abstract: Despite the wealth of knowledge in the field of oral corrective feedback, empirical evidence is still scarce regarding the EFL teachers' OCF perceptions and practices in Saudi Arabian context. This study therefore, sought to gain an understanding of teachers' use of oral corrective feedback $(O C F)$ in the Saudi Arabian EFL context. The following two questions guided the study: 1) According to teachers, what are the methods/strategies by which they provide oral corrective feedback (OCF) in the Saudi Arabian EFL context? 2) Is the teachers' oral corrective behaviour in this context informed by the research? For this purpose, a short questionnaire was designed and distributed among EFL instructors in Saudi Arabia. The research paper suggests that the OCF practices of EFL teachers in Saudi are mostly inline with the research.

Keywords: Corrective feedback; error correction; spoken errors

\section{INTRODUCTION}

For several decades, error correction has been an area of interest in the field of second language acquisition. The preponderance of research in corrective feedback illustrates its pedagogical and theoretical significance (Li, 2014). Numerous researches have been conducted investigating when, which and how learners' spoken errors should be corrected and who should be correcting them (Ellis 2009, Lightbown and Spada 1999). It is also evident from a review of the relevant literature that the researchers as well as practitioners have frequently disagreed on these questions. Nonetheless giving feedback on students' errors is one of the tasks every teacher is confronted with everyday. This paper reports on a small-scale research, which was conducted to gain insights into EFL teachers' oral corrective feedback (OCF) practices in a Saudi Arabian context.

Griffiths (2007) maintains that teachers' play a pivotal role in the process of teaching and learning. Therefore, investigating their practices is crucial, since these practices have the potential to impact the process of teaching and learning. Lyster et al. (2013) maintain that investigation on corrective feedback (CF) practices can lead to more effective teaching practices. Therefore, it is no surprise that a large body of research has analysed teacher practices in providing corrective feedback. However, research carried out in the Saudi Arabian context is still scarce. The studies, which have explored this topic in this region, have been limited to written corrective feedback and OCF has been a neglected area. Also, the few studies, which have been carried out about OCF, have only focused on 
students' perspectives and preferences regarding OCF. For example, Mustafa (2012) investigated Saudi students' opinions about the feedback they receive, and about their perceptions on what constitutes helpful feedback. However, the study was restricted to written corrective feedback. Such researches support Griffiths (2007) view, who argues that the variables related to teachers have not been explored sufficiently in comparison to the attention learners' issues have received.

The Saudi EFL teacher population is by its nature more heterogeneous than that of any other EFL context, with considerable variation in age, previous academic study, countries of origin, mother tongue and working experience. Every year, thousands of EFL instructors are employed from all over the world. Teaching practice in Saudi Arabia, therefore, is of a varied nature. During my assignment as an EFL instructor in Saudi Arabia, I noticed that the ways in which EFL instructors respond to spoken errors varies greatly. Some teachers corrected every grammatical error, while others chose to focus on pronunciation errors to a great extent. Some provided prompt corrections; others waited till the end of the lessons to provide the corrective feedback. After seeing this wide variety in the ways teachers provide corrective feedback, I decided to further investigate, in a small research project, the ways in which teachers respond to adult learners' spoken errors in this context. The findings of this research will hopefully inform the teacher trainers, university supervisors and the Head of the Preparatory Year Program to help them take measures in order to make teaching and learning more effective. Finally, this study aims to answer the following research question:

1. According to teachers, what are the methods/strategies by which they provide oral corrective feedback (OCF) in the Saudi Arabian EFL context?

\section{RESEARCH METHOD}

To answer the above questions a cross-sectional study was designed. The research questions called for straightforward descriptive answers, therefore, a survey method was chosen. In order to gain an understanding of teachers' practices, it was essential to collect the information from a sample of individuals through their responses to questions. Therefore, questionnaires were used for gathering data. The advantages of questionnaires have been discussed by several researchers and it has been considered an effective tool for gathering self-report data on preferences, attitudes and judgments (Hyland, 2002). One of the reasons for using questionnaires was for their time-efficient nature; they do not take a long time to administer and often a large number of respondents can be reached. Other research tools such as interviews or class observations were not feasible for a project of this size. Questionnaires are also easy to analyse and provide a great degree of 'precision and clarity' (Hyland, 2002). Also, the anonymity questionnaires offer enables the respondents to answer honestly without a fear of losing face (Basturkmen, 2010). This feature of questionnaires facilitated some of the research questions. For example, some questions about background, experience or teaching qualification would not have been comfortable in face-toface interviews and were not likely to yield honest responses. Finally, another reason this instrument was chosen was that small-scale researches, such as this, 
can particularly benefit from questionnaires in order to gain insights on issues that can be used to create interesting research topics which otherwise cannot be anticipated by researchers (Session Notes, MA TESOL Research methods 2012).

Taking into account the previous research on the topic, a questionnaire was designed. A literature review is beyond the scope of this essay, however, it should be noted that the questions attempted to cover most of the controversial areas in the research related to OCF. An attempt was made to ensure that it would yield enough data, without overburdening the respondents (Hyland, 2002). Hyland points out the importance of a carefully constructed and piloted questionnaire. Although piloting was not viable in this case, it was ensured that the questions were clear and were not leading to any ambiguity. In addition, considering that the participants differed significantly in their English language proficiency, it was written in plain English and jargon was avoided. The questionnaire had a clear title to provide the respondent with initial orientation. Dörnyei suggests that a questionnaire title helps to activate 'various content schemata' of the respondents (2003, p. 25).

The questionnaire consisted of 22 closed questions and 2 open questions. The open questions were related to the personal information about the participants as using multiple choice would have taken more space on the questionnaire. The majority of the items were closed questions. The advantage of closed questions is that the answers are easier to code and quicker to analyse. The sequence of questions on the survey was given special attention and demographic questions were left till the end of the questionnaire. The full questionnaire is included in Appendix A. The questionnaire consisted of two categories of questions as follows:

1. Teachers practices - These questions examined the classroom practices as regards to OCF. Questions used Likert scale giving the respondents options of never, sometimes, often and always.

2. General demographic questions-Teacher's personal data - age, education and EFL teaching experience etc.

The questionnaire began with a set of general instructions, stating why and how the questionnaire is administered etc. Further, the respondents were guided in the survey by transitional instructions about each section. The questions were mainly close ended and an exhaustive list of responses was provided. Wherever required, residual 'other' was used to increase flexibility in the response categories.

Furthermore, as regards to the administration of the questionnaires, the researcher was not working at the time of conducting the research and therefore was unable to gain access to educational institutes to administer the survey. Therefore, using Google Forms, online questionnaires were sent to the participants through emails and the professional networking site, LinkedIn. The questionnaire was also posted on the local teachers' groups using the social networking site, Facebook. The use of online surveys allowed the researcher to access the EFL teachers in Saudi Arabia conveniently. Also, as a female 
researcher, the male EFL teachers in the country were a hard-to-reach population due to the country's Islamic laws pertaining to gender segregation; the online survey allowed the researcher to overcome this issue. It also enabled the researcher to save time by reaching a large number of people in a short period of time. Enlisting several advantages of online survey methods, Wright (2005) asserts that online surveys may also save time by enabling researchers to gather data while they work on other tasks.

The survey was sent to 85 EFL instructors and the response rate was $56.47 \%$ with 48 responses in a short period of three days. The respondents came from a wide range of educational and cultural background. Twenty-two of the participants were Arabs, 12 were North American and the rest were from Asian and European background. If we divide them according to their linguistic backgrounds, 16 teachers were native speakers of English and the rest were nonnative speakers of English. The participants also differed in their level of education ranging from Bachelors to EdD.

The study was undertaken in accordance with Oxford Brookes University's regulations on ethical approval. The participants received clearly communicated information about the purpose of the research from the researcher prior to filling the questionnaire (Appendix A). Another issue that needed careful attention was that it has been suggested that respondents can over report on what they consider as a positive aspect and under report on a negative one (Dörnyei, 2003). Therefore, in order to avoid the 'respondents' social desirability bias' an 'explicit promise' (Dörnyei, 2003, p. 23) was included on the questionnaire. This was an attempt to ensure the respondents the anonymity of their responses. It was also made clear that there are no right or wrong answers and the information obtained is solely for the research purposes. The respondents were also offered a summary of the research findings if they would like to receive it.

Upon completion of the data collection, survey responses were exported from Google Forms to a spread-sheet in Excel format. For the analysis of the data, a data analysis tool Tableau was utilised. Hyland (2002) enlists several statistical tests, which are used in research; however, he also recognises that for small-scale research simple descriptive measures are often used. Therefore, to distinguish general distinctive features of the data, descriptive measures such as percentage were employed.

\section{FINDINGS AND DISCUSSION}

In this section, the data analysis results are interpreted and discussed in relation to the research questions set out in the introduction, and an attempt has been made to weigh the findings of this study against the findings of the existing research and the views of the scholars. This section is divided into two parts and each of these parts deals with one of the two research questions. The important findings of the research are attached in Appendix B. It should be noted, however, that a detailed analysis of the findings is beyond the scope of this essay. Therefore, only the salient parts of the data have been discussed. 
The first part of the questionnaire investigated teachers OCF practices. This part can further be divided into four sections.

Who provides the OCF?

The findings show that these teachers gave preference to self and peercorrection. Self-correction was used always or often by around $48 \%$ teachers. Similarly $43.75 \%$ participants used peer-correction with the same frequency. Lynch supports the idea of learners correcting their own errors and considers this 'enlightening' (1997, 324). This is also in accordance with Lyster et al.'s view (2013), who associate positive learning outcomes with self-repair.

Which oral errors are corrected?

Figure 1. Which types of errors are corrected?

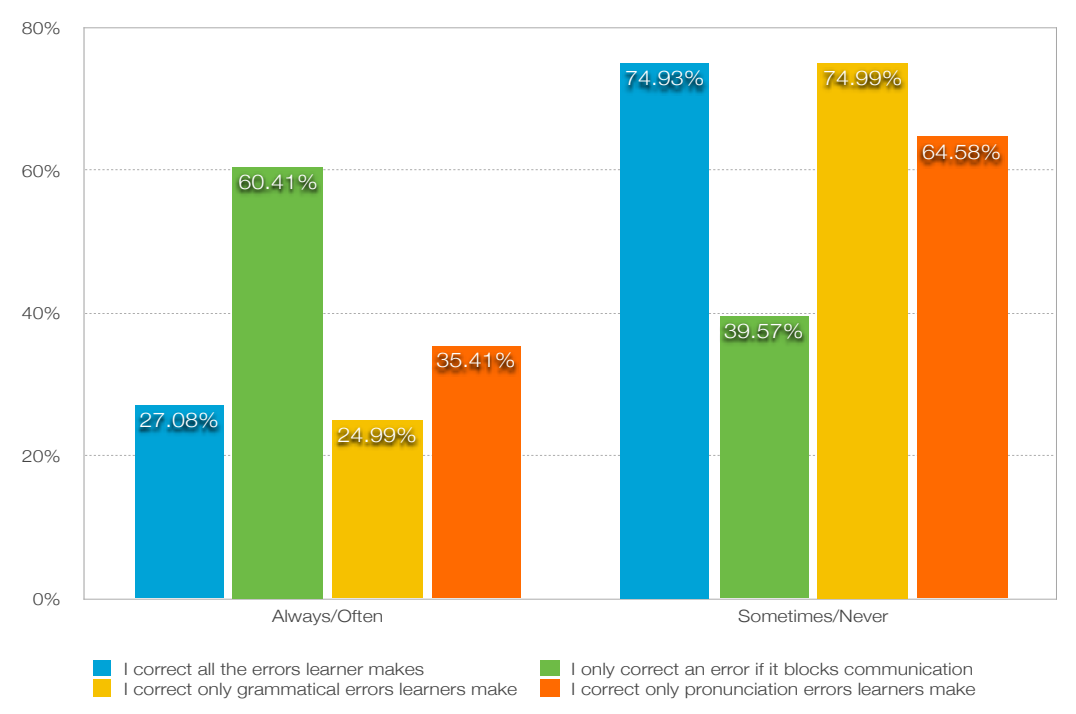

The findings of this area are also in agreement with the wider research as a large majority of the participants $(60.41 \%)$ believed that they always or often only corrected the errors that block communication. Grammatical and pronunciation errors were only corrected sometimes by the majority of the teachers $(74.99 \%$ and $64.58 \%$ respectively). At the same time, $25 \%$ of the teachers believed that they never corrected pronunciation errors (See Table 2). What is evident from the findings is that these teachers show selectivity when providing OCF, which is inline with the research that recommends selectivity in correction (Walz, 1982; Ellis, 2009). In accordance with Walz's view, Hyland (2002) points out that corrective feedback obtains the desired objective if errors are corrected selectively.

When are the oral errors corrected?

As regards to offline versus online feedback, it is difficult to draw any conclusions from the data collectively as these practices were extremely varied. 
These contrasting views of the teachers about delayed or immediate CF are also in consistence with the views of the SLA scholars and methodologists who have consistently differed in the efficacy of immediate or delayed OCF (Harmer, (video), Lynch 1997). Ellis maintains that 'there is no evidence to show that immediate correction is any more effective than delayed' $(2009$, p. 11). Likewise, Hyland (2002) recognises that no consensus can be reached as to when to correct errors and argues that each teacher will have his or her own preference.

How are the oral errors corrected?

Figure 1. Error correction Strategies

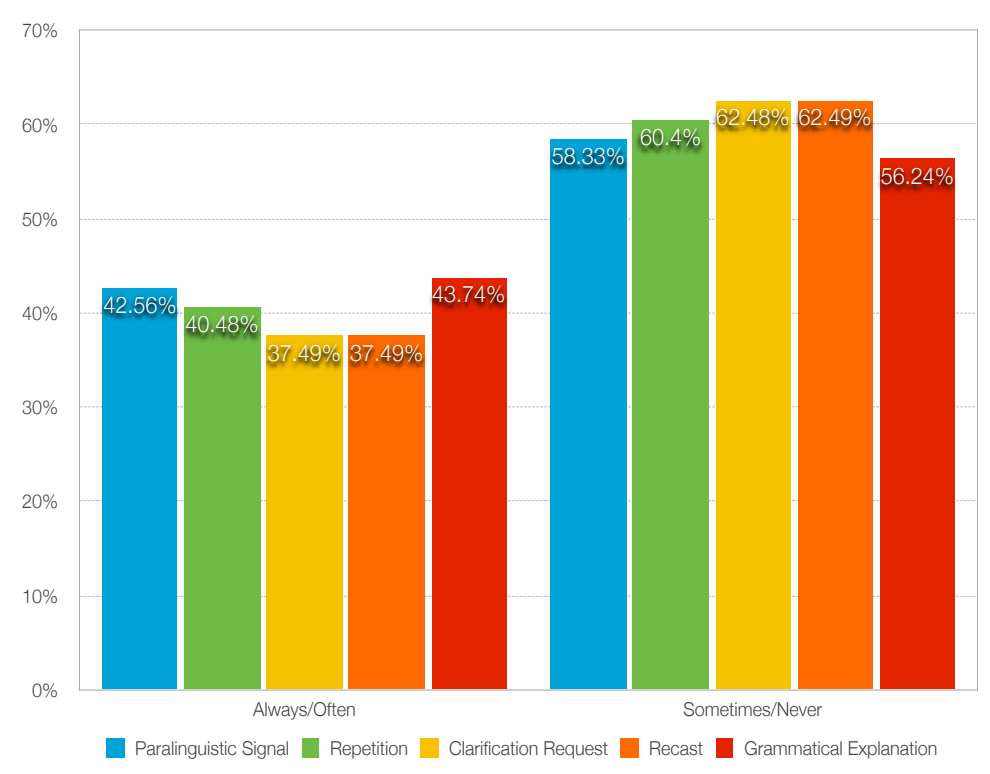

As to the response of the questions related to how the spoken errors are corrected in Saudi Arabian EFL classrooms, it is evident that the teachers use both implicit and explicit types of strategies including paralinguistic signals, clarification requests, recasts and grammatical explanations. The majority of the teachers $(43.74 \%)$ showed a preference for an explicit strategy and reported that they always or often corrected spoken errors by providing grammatical explanation. This is in harmony with the research since a large number of benefits have been associated with explicit corrective strategies (Lyster et al., 2013). In contrast, a similar number of teachers $(42.56 \%)$ showed preference for an implicit strategy and stated that they employed paralinguistic signals always or often. Such practices are also supported by several researchers such as Lynch (1997) who favours 'nudging' (p. 324) the learners towards a solution instead of providing them with a correct answer. A possible explanation for the use of an implicit OCF strategy has been provided by Lyster and Ranta (2013) who suggest that the teachers' extensive use of implicit strategies can be attributed to the teachereducation literature and courses, which often highlight the possible negative affective impact of explicit $\mathrm{CF}$ strategies. One unanticipated finding of the research was that recasts, which has been a controversial strategy in the SLA research, were used only sometimes or never by the majority of the teacher 
(62.49\%). This OCF behaviour of the participants differs from the findings of other researches. For example, Russell (2009) found recasts to be the most common form of oral corrective strategy used by foreign language teachers. Overall the strategies used by foreign language teachers in Saudi Arabia corroborates the ideas of Lyster and Ranta (2013) who make a case for using a variety of CF strategies.

\section{CONCLUSION}

The purpose of this study was to investigate teachers' oral corrective practices in Saudi Arabia. Although the study helped to gain insights into teachers' OCF practices in Saudi Arabia, it has a few limitations. One limitation of this study was the small sample size. Small samples do not permit generalisation to a larger population. It has been argued that increasing the sample size increases its reliability.

To sum up, this study offers valuable insights into how spoken errors are corrected in the Saudi Arabian context. Information from the current study would be of value to teacher education coordinators seeking to determine more beneficial techniques for teacher training. A note of caution is due here since the study was not triangulated. To develop a full picture of OCF practices of EFL teachers in Saudi Arabia, additional studies will be needed. Also, further research should be done to investigate the determining factors of the teachers' OCF practices.

\section{REFERENCES}

Basturkmen, H. (2010). Developing courses in English for specific purposes. Basingstoke: Palgrave Macmillan.

Dörnyei, Z., (2003). Questionnaires in second language research: Construction, administration, and processing. Mahwah, NJ: Lawrence Erlbaum Associates.

Ellis, R (2009). Corrective feedback and teacher development. L2 Journal, 1(2009), 3-18.

Griffiths, C. (2007). Language learning strategies: students' and teachers' perceptions. ELT Journal, 61(2), 91-99.

Harmer, J (video) Interview with Jeremy Harmer - Jeremy talks about extensive reading and error correction in the communicative approach. Harrogate Online, The $48^{\text {th }}$ Annual International IATEFL Conference \& Exhibition

Hyland, K. (2002). Teaching and researching writing. London: Longman.

Li, S. (2014). Oral corrective feedback. ELT Journal, 68(2),196-198.

Lightbown, P. M., \& Spada, N. (1999). How languages are learned. Oxford, UK: Oxford University Press.

Lynch, T. (1997). Nudge, nudge: teacher interventions in task-based learner talk. ELT Journal, 51 (4): 317-325. 
Lyster, R., \& Ranta, L. (2013). Counterpoint piece the case for variety in corrective feedback research. Studies in Second Language Acquisition, 35, $167-184$.

Lyster, R., Saito, K., \& Sato, M. (2013). Oral corrective feedback in second language classrooms. Language Teaching, 46(1), 1-40.

Mustafa, R. (2012). Feedback on the feedback: Sociocultural interpretation of saudi esl learners' opinions about writing feedback. English Language Teaching, 5(3), 3-15.

Russell, V. (2009). Corrective feedback, over a decade of research since Lyster and Ranta (1997): Where do we stand today? Electronic Journal of Foreign Language Teaching, 6(1), 21-31.

Session Notes, MA Research methods 2012. Oxford Brookes University.

Walz, C. (1982), Language in education-theory and practice. Center for Applied linguistics: Washington. Available at http://files.eric.ed.gov/fulltext/ED217704.pdf [Accessed on 23/02/2014].

Wright, K. (2005). Researching internet-based populations: advantages and disadvantages of online survey research, online questionnaire authoring software packages, and web survey services. Journal of ComputerMediated Communication (10)3. 